\title{
Landscape dynamics and resulting species interactions: the cod-capelin system in the southeastern Bering Sea
}

\author{
Lorenzo Ciannelli1 ${ }^{1,3, *}$, Kevin M. Bailey ${ }^{2}$ \\ ${ }^{1}$ University of Washington, Joint Institute for the Study of Atmosphere and Ocean, Seattle, Washington 98105, USA \\ ${ }^{2}$ Alaska Fisheries Science Center, NOAA, Seattle, Washington 98115, USA \\ ${ }^{3}$ Present address: Centre for Ecological and Evolutionary Synthesis (CEES), Department of Biology, PO Box 1066, Blindern, \\ University of Oslo, Oslo 0316, Norway
}

\begin{abstract}
Capelin are a major component of cod diet in many ecosystems of the North Atlantic. In the Bering Sea, however, the percentage of capelin found in Pacific cod stomachs is negligible. We hypothesize that the landscape (or 'seascape') features of hydrography and bathymetry of the Bering Sea impose a constraint on the distribution of cod and capelin that contributes to their spatial segregation and ultimately, to their uniquely weak trophic link. We analyzed a long-term data collection (1972 to 2001) on Pacific cod and capelin catches and feeding interactions, and developed a new metric to quantify the spatially explicit overlap between a predator and a prey. Our analysis indicates that cod and capelin distributions respond to the thermal conditions of the Bering Sea. Typically, a frigid water mass is present on the middle portion of the shelf, and cod distribution is confined to the southern side of the cold pool, while capelin is confined to the north. However, in warm years the middle shelf is penetrated by thermal gateways (between 1 and $6^{\circ} \mathrm{C}$ ), allowing cod to invade the capelin habitat. In this situation, when cod and capelin overlap, cod feed heavily on capelin. The annual index of cod and capelin overlap is correlated with the Pacific Decadal Oscillation (PDO) index, a climate indicator of the North Pacific. The width of the thermal gateways in the middle shelf is also correlated with the PDO. These results point to a direct causal link, from climate and thermal conditions of the Bering Sea shelf, to cod and capelin distribution, and ultimately to their overlap and trophic interactions.
\end{abstract}

KEY WORDS: Pacific cod $\cdot$ Capelin $\cdot$ Bering Sea $\cdot$ Predator-prey overlap $\cdot$ Landscape ecology - Resale or republication not permitted without written consent of the publisher

\section{INTRODUCTION}

In terrestrial ecosystems, the role of the landscape on species distributions and ecological processes is wellestablished (e.g. Turner 1989), but this field is less developed in oceanic ecosystems (Taylor et al. 2002). The landscape over which a species ranges is described by its characteristics, such as fragmentation, patchiness and continuity, as well as by consideration of how it may change on temporal and spatial scales. Over time, landscapes may vary in character and continuity due to natural or man-made disturbances. The ocean landscape (perhaps more aptly termed 'seascape', e.g. Barlett \& Carter 1991) is not just a result of topography (or landforms), but involves the interaction of currents, hydrography, bathymetry and atmospheric conditions, and thus the ocean landscape is labile. The landscape of pelagic ecosystems is critical to their functioning, affecting habitat extent, transport of planktonic life stages, corridors between different habitats, retention features, and aggregations of predators and prey (e.g. Rose \& Leggett 1990). The study of ecological processes influenced by the landscape, such as predator-prey interactions, falls within the 
realm of landscape ecology. One aspect of species interactions is the role of landscape dynamics in the overlap of predator and prey distributions.

In many of the world's northern seas, the predatorprey relationship of cod Gadus spp. and capelin Mallotus villosus results from their overlapping distributions (Lilly 1994, Rose \& O'Driscoll 2002), and very often this relationship forms a trophic interaction of high relevance for the entire ecosystem (Carscadden et al. 2001, Dolgov 2002). In the Barents Sea for example, Atlantic cod Gadus morhua feed on capelin all year round. The importance of capelin in the cod diet varies from year to year, and the amount ranges from 11 to $56 \%$ (Nakken 1994). Capelin are also a critical component of cod diet in other areas where their distributions overlap, including the northwest Atlantic (Lilly 1991) and the seas around Iceland (Palsson 1997) where capelin is about 10 to $40 \%$ of and 25 to $90 \%$ of the cod annual average diet, respectively.

In contrast, capelin play a relatively insignificant role in the diet of the Pacific cod Gadus macrocephalus in the eastern Bering Sea. Generally, capelin make up about $1 \%$ of the diet of cod in the Bering Sea (Mito 1974, 1979, Livingston 1991, Livingston \& deReynier 1996). While relatively little is known about the overall capelin abundance in the Bering Sea, capelin have been historically identified as a key link in the food chain. Capelin are an important component of the diet of many seabirds, seals and whales (Frost \& Lowry 1981, Lowry \& Frost 1981, Springer et al. 1987, Loughlin et al. 1999). Furthermore, declines of capelin stocks have been proposed as a potential cause of a declining northern fur seal population in the Bering Sea (Sinclair et al. 1994). Based on diet composition of predators in topdown ecosystem models, the minimum to maximum equilibrium biomass levels of capelin are estimated to range from 3.5 to 5.1 million tons (Laevastu \& Larkins 1981). Aside from juvenile pollock, these calculations make them the most abundant forage fish in the eastern Bering Sea. In addition, from an analysis of trawl surveys, Brodeur et al. (1999) list juvenile pollock, Pacific herring and capelin as the most important forage species in the eastern Bering Sea.

The Bering Sea landscape is heterogeneous and complex, and plays a major role in the distribution of species and their productivity (Fig. 1). The continental shelf of the eastern Bering Sea is broader than $500 \mathrm{~km}$. It is divided into 3 distinct pelagic zones based on hydrography: the outer, middle and inner shelves. These domains are separated by 2 frontal regions at the 50 and $100 \mathrm{~m}$ isobaths that are created by tidal interactions with topography; the outer shelf lies seaward of the $100 \mathrm{~m}$ front, the middle shelf zone is between the 50 and $100 \mathrm{~m}$ fronts, and the inner shelf is inland of the $50 \mathrm{~m}$ front (Stabeno et al. 1999; Fig. 1). Different plankton assemblages are found in each zone (Cooney 1981, Cooney \& Coyle 1982). The Bering Sea has been impacted by shifts in climate regimes; for example, a climate regime shift that occurred in the late 1970s had dramatic effects on biological communities (Benson \& Trites 2002). A weaker shift may have occurred in 1989, but the effects were apparently not long-lasting (Bond et al. 2003).

In this study, we examine the link between landscape dynamics, climate forcing and ecological interactions between cod and capelin in the eastern Bering Sea. We argue that the features of the landscape in the Bering Sea constrain their overlap, resulting in a uniquely weak trophic link compared to other regions. Furthermore, we hypothesize that climate forcing can influence the ecological interactions between cod and capelin by modifying the landscape constraint of their distributions. Through this study, we demonstrate the importance of spatial dynamics on oceanic species interactions, an outlook that may provide a fresh viewpoint of the link between landscape, climate and species variability in marine ecosystems.

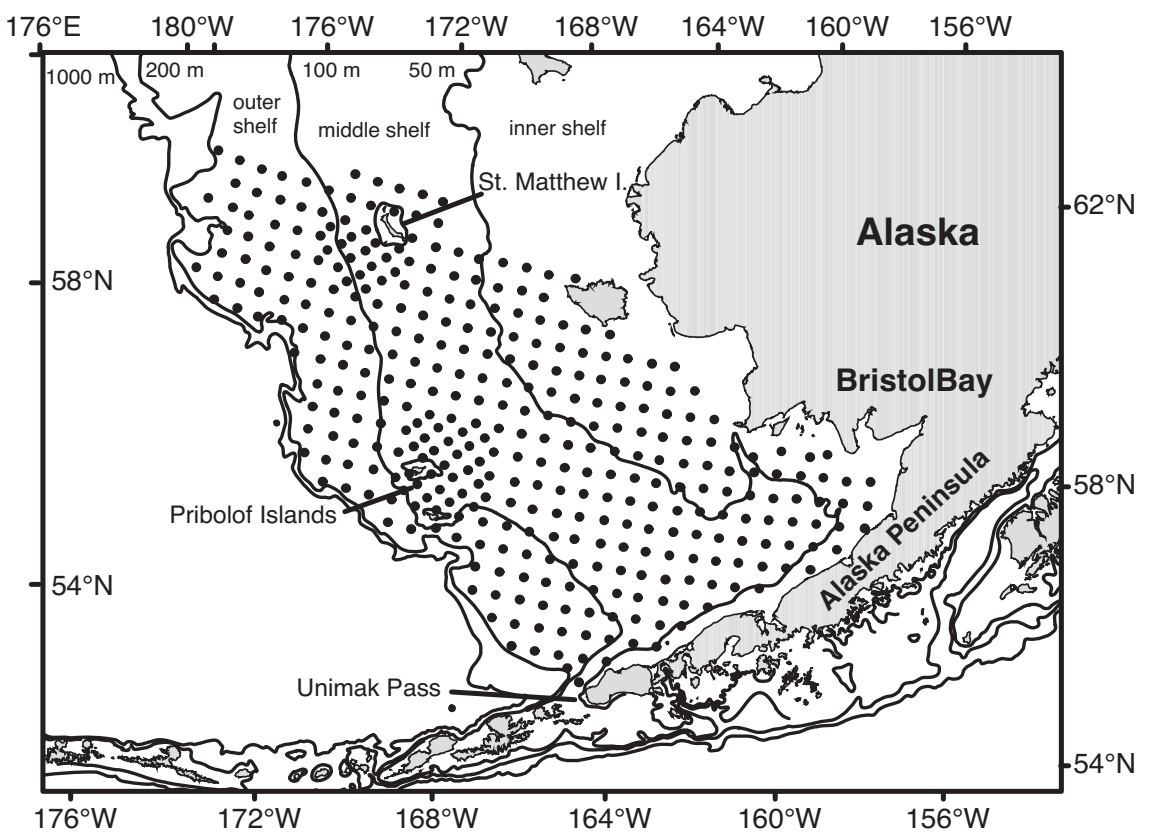

Fig. 1. Map of the eastern Bering Sea with the location of the surveyed grid from 1979 to 2001 . From 1972 to 1978 , the surveys varied from this standardized plan 


\section{MATERIALS AND METHODS}

Data collection. Data on Pacific cod and capelin distribution (i.e. catch at location) were taken from the bottom trawl survey of the Alaska Fisheries Science Center (AFSC, see Nebenzahl 2001; Fig. 1). The sampling gear consisted of an 83-112 eastern otter trawl, with $25.3 \mathrm{~m}$ headrope, $34.1 \mathrm{~m}$ footrope and $32 \mathrm{~mm}$ codend mesh liner. Sampling occurred during the summer months, typically from the end of May to the end of July. The sampling grid of the AFSC survey has been the same since 1979, but collections are available on an annual basis since 1972. The post-1979 sampling plan includes a total of 356 stations, from the 20 to the $200 \mathrm{~m}$ isobath, over a regular grid with stations spaced 20 nautical miles apart (Fig. 1). In the vicinity of St. Matthew and the Pribilof Islands sampling was more intense. The surveyed grid only covers the southern portion of the eastern Bering Sea shelf, and capelin can extend further to the north and west (Naumenko 1996). However, for studying factors affecting the overlap between cod and capelin in the eastern Bering Sea, the surveyed region should be sufficient, as cod are most abundant in the sampled area (Bakkala 1984). Before 1979, the coverage of the survey was variable, particularly over the inner shelf, while the middle and outer shelf were, for the most part, fully sampled. In our analysis, we combine data from the entire sampling period, i.e. 1972 to 2001 , and discuss the potential bias introduced by the variable sampling coverage before 1979

At each station, along with capelin and cod catches, bottom depth, and bottom and surface temperatures were also recorded. Catch per unit effort (CPUE) of capelin and cod was recorded as biomass over area swept $\left(\mathrm{kg} \mathrm{ha}^{-1}\right)$. We assume that the reported capelin catches, even though they are not accurate estimates of the actual abundance, are appropriate as relative indices of abundance, and therefore are suitable to study distribution patterns. In addition, we assume that since capelin are pelagic, they are caught in the bottom trawl net while the net is hauled back (i.e. catches are integrated over the water column). Thus, any change in capelin vertical distribution is not likely to influence their catchability. Indeed, in a year where both pelagic and demersal trawl surveys were conducted, the distribution patterns were nearly identical (Brodeur et al. 1999).

The cod CPUE considered in this study only includes specimens of Age 3 and older, as younger juvenile cod feed predominantly on macrozooplankton prey. The partition between age groups of cod catches was based on a year-specific age-length key. Typically, cod of $340 \mathrm{~mm}$ (standard length) and above are Age 3+. From 1985 to the current surveys, cod length was recorded in over $95 \%$ of the stations, from 1981 to 1985 in more than $70 \%$, and from 1972 to 1980 the percentage varied from $0 \%$ (in 1974) to $76 \%$ (in 1979). For stations where no lengths were recorded, we applied the average length distribution of the entire survey to the stations' missing data. For the survey in which cod lengths were not recorded (i.e. 1974), we applied an average length distribution derived from the 1973 and 1975 surveys.

Incidences of cod feeding on capelin (i.e. percent by weight of capelin found in cod stomachs) were taken from the AFSC diet database (Livingston \& deReynier 1996). The database includes stomach content analysis of commercially important groundfish species of the Bering Sea. Records are available on an annual basis and data for Pacific cod date back to 1975.

Data analysis. Spatial and annual averages of cod, capelin and bottom temperatures were assessed as follows:

spatial averages: $\quad X_{a}^{s}=\frac{\sum_{t=1}^{T} X_{a, t}^{s}}{T}$

annual averages: $\quad X_{a, t}=\frac{\sum_{s=1}^{S_{t}} x_{a, t}^{s}}{S_{t}}$

where $X$ is the averaged variable specified by the subscript $a(1=\operatorname{cod}, 2=$ capelin, $3=$ bottom temperature, $1 \cdot 2$ = overlap metric between cod and capelin), $x$ is the value of the variable $a$ recorded at the station $s$ and year $t, T$ is the total number of years sampled, and $S_{t}$ is the total number of stations sampled during the year $t$. By applying Eq. (2) to a pre-selected group of stations, we estimated annual averages of cod and capelin over sub-portions of the sampled areas. These are the 'inner-middle shelf' defined as the area north of $57.5^{\circ}$ latitude and shallower than $70 \mathrm{~m}$ depth, and the 'outer shelf' defined as the areas south of $57.5^{\circ}$ latitude.

We hypothesize that the formation of habitat junctions or corridors between the outer and the inner shelf allows a greater overlap between cod and capelin. Critical and ephemeral (i.e. variable on an annual base) habitat junctions in the Bering Sea are linked with the thermal condition throughout the shelf. For example, in years when bottom temperature is high, there are areas between the outer and middle shelf which are within the 'comfort zone' of Pacific cod (i.e. $>1^{\circ} \mathrm{C}_{i}$ Perry et al. 1994), and which may allow cod to invade the middle and inner shelf. In this study, we focus on the width of the areas between 1 and $6^{\circ} \mathrm{C}$ (herein referred to as 'thermal gateway') measured across the middle shelf (i.e. 50 to $100 \mathrm{~m}$ isobath) of the Bering Sea. To assess whether the width of the gateway can influence cod and capelin movements, we 
estimated, by applying Eq. (1), cod and capelin average distributions over periods of 'narrow' and 'wide' thermal gateways. Narrow thermal gateways were those with width value below the median and viceversa for wide gateways.

We assessed the overlap between cod and capelin $\left(x_{1 \cdot 2}\right)$ as the product between the distance-weighted cod and capelin CPUE $\left(\hat{x}_{1}, \hat{x}_{2}\right.$, respectively) at the examined station $s$ :

$$
X_{1 \cdot 2, t}^{S}=\hat{X}_{1, t}^{S} \hat{X}_{2, t}^{S}
$$

In turn, the distance-weighted CPUE was equal to:

$$
\hat{\boldsymbol{X}}_{a, t}^{s}=\frac{\sum_{i=1}^{N} x_{a, t}^{s, i} w^{s, i}}{\sum_{i=1}^{N} w^{s, i}}
$$

where $N$ is the total number of sampled stations within a circle centered in $s$ with radius equal to $d_{\max }$. Each sampled station within the circle defined by $d_{\max }$ is uniquely identified by the superscript $i$. In our application, $d_{\max }$ was fixed to $50 \mathrm{~km}$. The weight coefficient $(w)$ of the $i$ th station is inversely proportional to its distance $(d)$ from the center of the circle $s$ :

$$
W^{s, i}=\frac{I_{i}}{\left(1+d^{s, i}\right)}
$$

where $I$ is an indicator variable equal to 1 if $d^{s, i} \leq d_{\text {max }}$ otherwise 0 .

We used the Pacific Decadal Oscillation index (PDO; Mantua \& Hare 2002) to represent climate variations in the Bering Sea region. Linear regression analysis was used to inspect the correlation between interannual dynamics of the PDO and the 2 new metrics developed in this study, i.e. width of the thermal gateway and cod-capelin overlap. Moreover, we used nonparametric regression analysis (i.e. generalized additive models, GAMs) to identify the factors affecting incursions of cod in the middle and inner shelf. The covariates of the GAM analysis were PDO, width of the thermal gateway, and annual average cod and capelin CPUEs throughout the sampling region. We tested for all possible combinations of second-order interactions using the multiplicative approach described in Hastie \& Tibshirani (1990) and applied in Ciannelli et al. (2004). Specifically, the interaction term was formed by the product between the 2 standardized and shifted interacting covariates. Covariates were shifted (i.e. a constant is added to their standardized series) so that their value was $\geq 0$, and consequently, their product becomes a monotonic increasing function. Our model selection criterion was based on a step-wise approach, aimed at minimizing the model generalized crossvalidation (GCV; Wood 2000). We initially included all the covariates (without interaction terms) in the GAM model of cod CPUE. Then we eliminated, one by one, all the covariates whose partial effect had the lowest significance level (i.e. high p-value). This process was repeated until the elimination of the covariate caused an increase of the model GCV. Finally, we examined all possible combinations of second order interaction terms among the selected additive covariates, and only retained the terms that caused a further decrease of the model GCV.

\section{RESULTS}

\section{Landscape features}

The coldest bottom temperatures are typically found along the middle shelf of the Bering Sea, forming a cold pool (Fig. 2). Warmer bottom temperatures are typically found in coastal zones and over the outer shelf. The pattern of bottom temperature distribution is strongly influenced by physical variables, such as bathymetry, ice cover, tidal and wind mixing. Specifically, warming of the bottom temperature near the coastal zone and offshore reflect tidal mixing of warmer surface water and advection of warm basin water onto the outer shelf, respectively. Cooling in the northern and central areas reflects the formation of the cold water mass due to ice over the middle shelf in winter.

The temperature of the cold pool changes from one year to the next. During warm years, the cold pool is less intense particularly in the area adjacent to the Alaska Peninsula and north of the Pribilof Islands (Fig. 2c). As a result, in some years, the pool $\left(<1^{\circ} \mathrm{C}\right)$ may lose its continuity and be found in 2 areas, one northwest of the Pribilof Islands and another cold tail over the southeastern side of the middle shelf. Hence, in warm years, there may be a formation of thermal gateways between the outer and the middle shelf; one gateway is observed along the Alaska Peninsula and another in the central portion of the middle shelf (Fig. 2).

\section{Spatial patterns}

From their mean distribution patterns, cod are found in 3 main aggregations in summer: one on the western side of the outer shelf in water 100 to $200 \mathrm{~m}$ deep, the second in the middle shelf northeast of the Pribilof Islands in water that is 50 to $70 \mathrm{~m}$ deep, and the third along the Alaska Peninsula (Fig. 3). In summer, capelin are distributed in the northern coastal region, typically in water shallower than $70 \mathrm{~m}$ (Fig. 3). In years when a frigid water mass is over the middle shelf and the thermal gateway is narrow, there is a tendency for cod to 

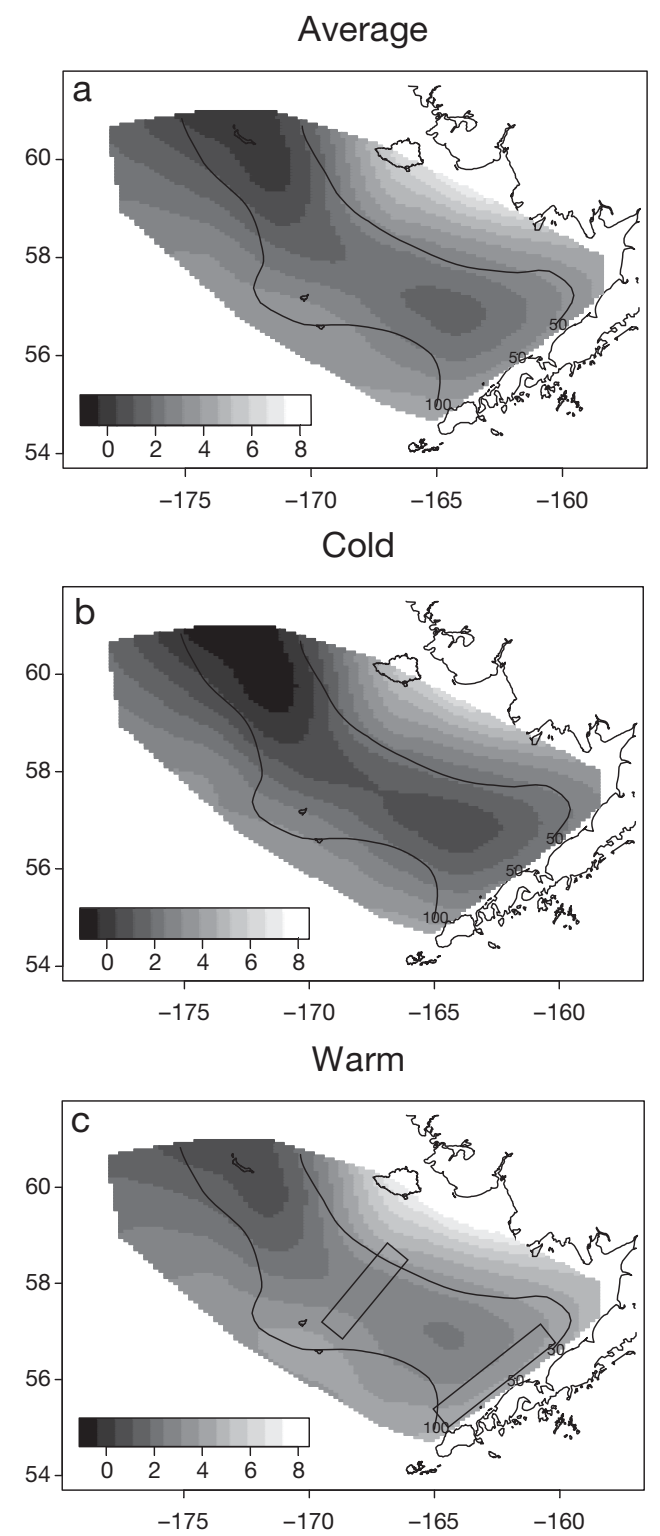

Fig. 2. (a) Spatial distribution of average bottom temperature during the 1972 to 2001 sampling period. (b,c) Bottom temperatures during 'cold' (b) and 'warm' (c) years. Warm years were defined as those with average middle shelf (50 to $100 \mathrm{~m}$ depth) bottom temperature equal to or greater than the median of the available temperature time series. Cold years were defined as below the median. (c) also shows a schematic (rectangles) of where the thermal gateways are likely to occur during warm years

be constrained to the outer region of the shelf, and to reside within a very narrow zone along the Alaska Peninsula. Conversely, when the whole shelf is warm and the thermal gateways are opened, cod over the middle shelf are distributed further north, and are found in higher densities along the Alaska Peninsula (Fig. 4). Capelin have an even clearer relationship with
Cod
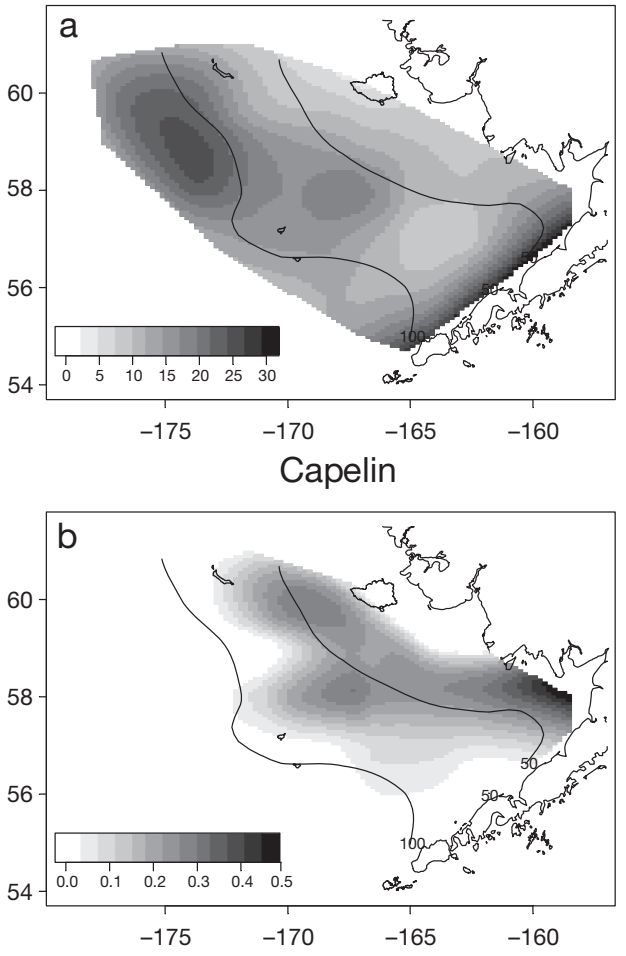

Fig. 3. Gadus macrocephalus and Mallotus villosus. Spatial distribution of (a) cod and (b) capelin average catch per unit effort (CPUE, $\mathrm{kg} \mathrm{ha}^{-1}$ ) during the sampling period 1972 to 2001

variation of thermal conditions over the middle shelf: in years with narrow thermal gateways, they move south and into Bristol Bay, while in years with large gateways, capelin move to the north and probably extend out of the survey region (Fig. 4).

Since 1975, a total of 3371 stations were sampled for diet analysis and 34269 cod stomachs were inspected. Of these, capelin was found in the diet of $92 \mathrm{cod}$ from 46 stations. When capelin were found in the cod stomachs, their average content was $59.2 \%$ by weight and the average capelin weight per fish stomach was $26.2 \mathrm{~g}$. However, in many of these cod stomachs (over $20 \%$ ), capelin was the only prey found. The area with the highest mean overlap of cod and capelin was in the coastal zone, primarily within the area of the capelin distribution (Fig. 5a). The locations where cod were feeding on capelin largely coincided with the areas of highest overlap among the 2 species (Fig. 5b).

\section{Interannual dynamics}

The time series of cod biomass in the Bering Sea (not shown here) surged in the late 1970s and early 1980s (Thompson \& Dorn 2003). In the 1990s, cod biomass 

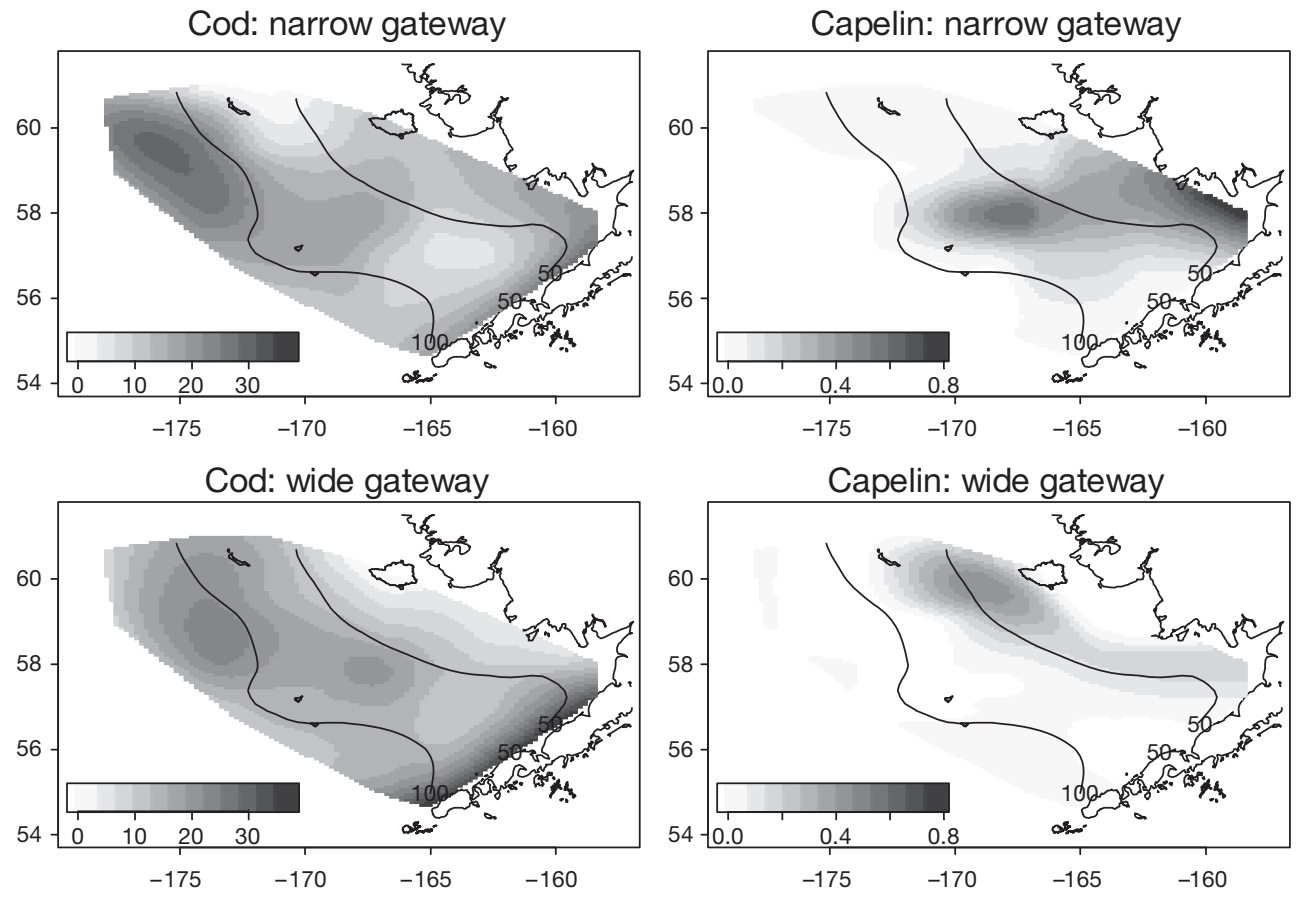

Fig. 4. Gadus macrocephalus and Mallotus villosus. Spatial distribution of cod and capelin CPUE (kg $\mathrm{ha}^{-1}$ ) during years with 'narrow' and 'wide' thermal gateways in the middle shelf. Years with narrow thermal gateways were those whose gateway width was below the median of the available time series, and viceversa for wide gateway years

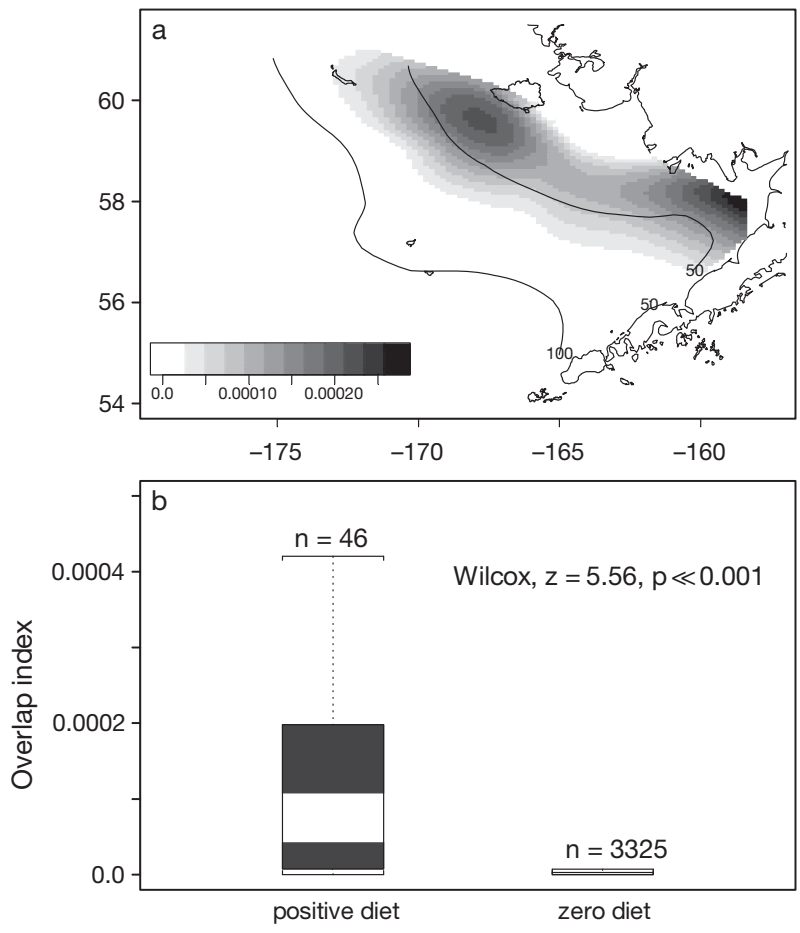

Fig. 5. Gadus macrocephalus and Mallotus villosus. (a) Spatial distribution of average overlap between cod and capelin, during the sampling period 1972 to 2001. (b) Average values of overlap between cod and capelin in the proximity of the stations where cod stomachs were analyzed (3371 stations). The 'positive cod' box refers to stations in which capelin was present in cod stomachs (46 stations), while the 'zero diet' box refers to stations without capelin in cod stomachs (3325 stations). The lower and upper margins of the box represent the first and third quartile, respectively. The central line is the median and the whiskers extend to $1.5 \times$ inter-quartile range declined, but still remained at a fairly high level compared to the pre-1980s values. Capelin CPUE was high in the early 1970s and after that decreased, remaining low (with occasional peaks) until the end of the analyzed time series (Fig. 6). Capelin below the $57.5^{\circ} \mathrm{N}$ parallel, declined sharply after the 1970 s and, for the most part, disappeared from the outer shelf. As a consequence, the latitude of the center of mass of capelin distribution shifted northward in the late 1970s, and stayed north throughout the duration of the available time series. The average locations of cod feeding on capelin also shifted northward during the course of the time series, while the percent of capelin found in cod stomachs (only of cod that were feeding on capelin) decreased (Fig. 6).

The GAM analysis revealed that cod incursions from the outer to the middle and inner shelf of the Bering Sea were non-linearly correlated with the amount of cod CPUE in the full survey area (estimated degrees of freedom 2.09) and its interaction with the PDO index (Fig. 7). The interaction term caused the cod CPUE in the middle and inner shelf region to roughly double its value going from years with lowest (e.g. 1975, 1999) to highest PDO index (e.g. 1983, 1987). The model explained $84.7 \%$ of the total interannual variance of cod CPUE over the middle and inner shelf. The PDO index was significantly correlated with the width of thermal gateways over the inner shelf (linear regression; $\mathrm{p}=0.034, \mathrm{r}=0.39$ ) and with the overlap index between cod and capelin (linear regression; $p=0.026$, $\mathrm{r}=0.40$ ). 

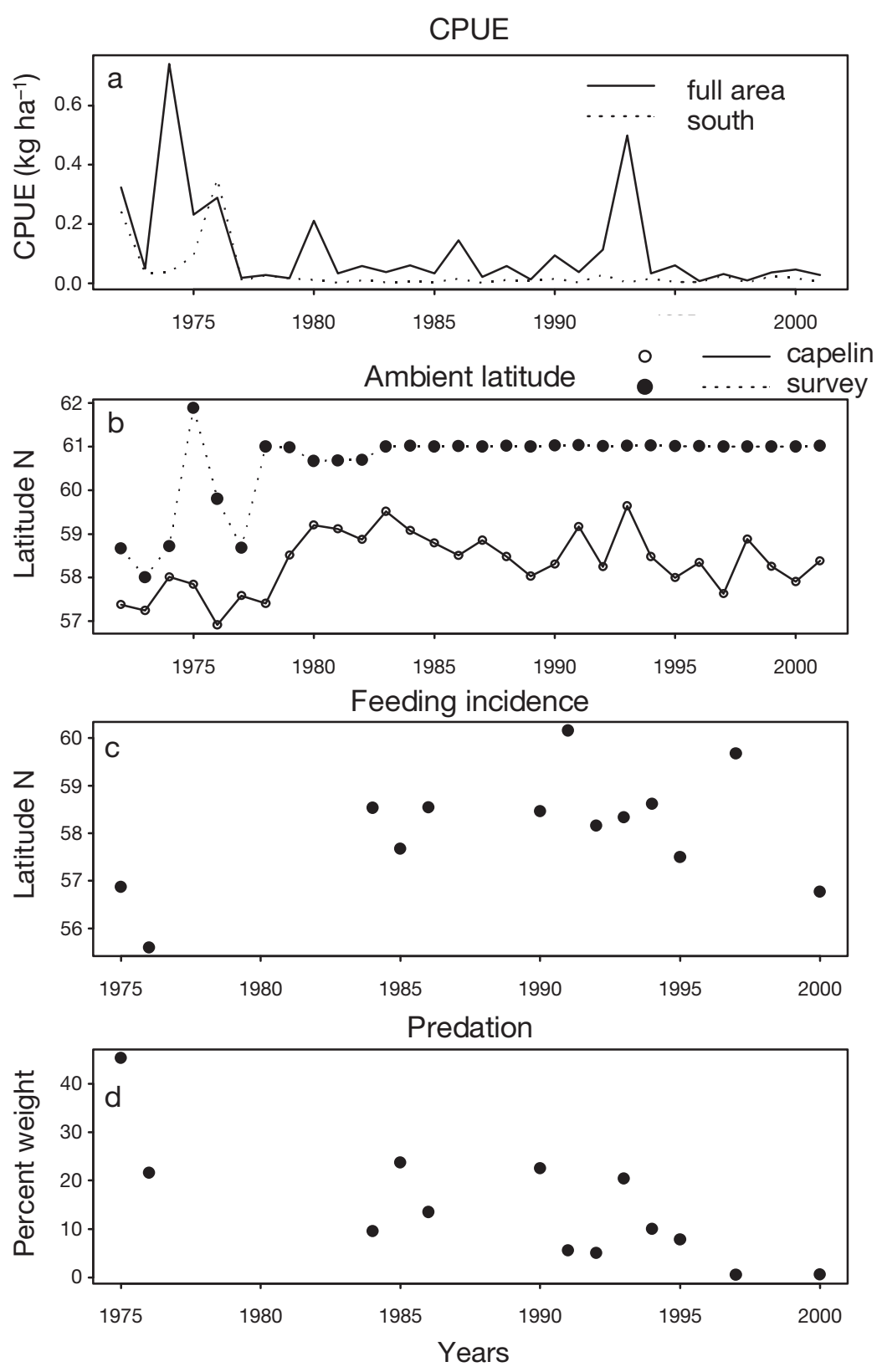

Fig. 6. (a) Time series of capelin catch per unit effort (CPUE) in the fullysurveyed grid ('full area') and the partial area south of $57.5^{\circ}$ latitude north ('south'); (b) latitude of capelin center of mass along with the northernmost extension of the sampling survey; (c) average latitude of the stations where capelin was found in cod stomachs (46 stations spread over 13 years); (d) average capelin content (\% weight) in cod stomachs (only cod stomachs containing capelin were included in the plot)

\section{DISCUSSION}

Our study demonstrates that the landscape features of the eastern Bering Sea contribute to the summertime spatial segregation between Pacific cod and capelin, resulting in a uniquely weak trophic interaction. These landscape features include both fixed (e.g. bathymetry) and labile (e.g. hydrography) components. Typically, in a cold year, a frigid water mass is present over the middle shelf region of the eastern Bering Sea. The cold pool persists through the summer and restricts the movement of cod into the inner and middle shelf regions, where capelin are more densely aggregated. However, during warm years when the cold water mass is less extensive, there are corridors for cod movement onto the inner shelf that are marked by the 1 to $6^{\circ} \mathrm{C}$ isotherm. From maps of both bottom temperatures and cod distribution patterns, there seem to be 2 main thermal gateways opened during warm periods: a northern route across the mid-shelf, north of the Pribilof Islands, and another along the Alaska Peninsula. Capelin distribution is also impacted by thermal regimes. In cold periods, capelin are distributed further south into Bristol Bay and in warm periods, they presumably shift northward and become relatively sparse in the survey region.

These distribution patterns largely control the predator-prey interaction between cod and capelin. In cold years, capelin are protected from incursion of predators by the cold barrier across the middle shelf. In warm years, predatory cod may migrate into the capelin habitat, but capelin are partially protected by shifting their distribution northward. However, when and where cod and capelin do overlap, cod prey heavily on capelin.

Climate may regulate the extent of cod migration and overlap with capelin, via modification of the thermal regime in the middle shelf of the Bering Sea. In our analysis, the PDO index was correlated with the degree of overlap between cod and capelin, the relative abundance of cod in the inner shelf and the width of the thermal gateway, suggesting that there was a direct causal link going from climate and thermal gateways to predatorprey overlap. However, other factors may have also contributed. For example, the non-linear effect (i.e. slightly convex) of cod from the fully surveyed region on that portion of the population found further north, is indicative of a positive density-dependent movement from the outer shelf to the middle and inner shelves (a density-independent effect would result in a linear 


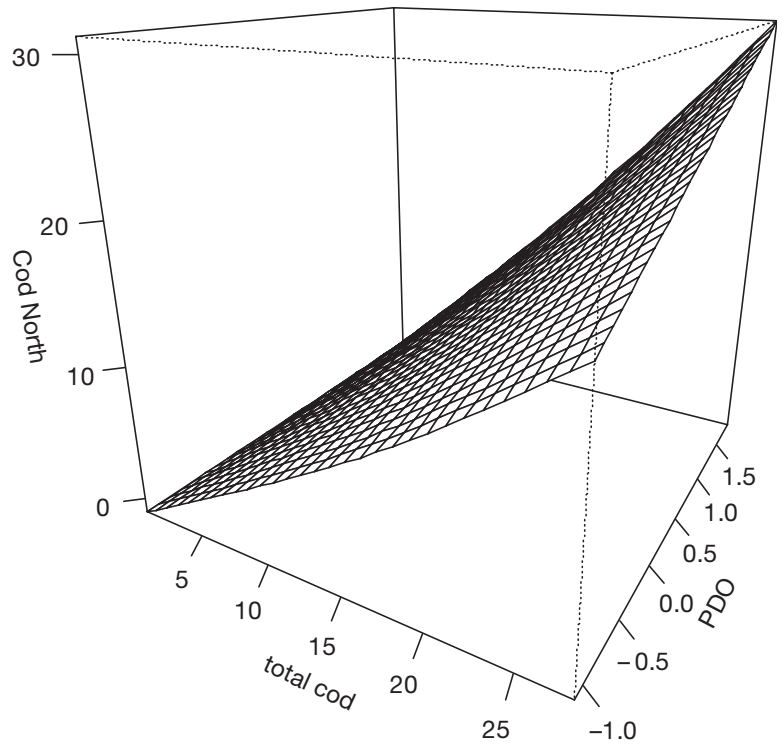

Fig. 7. Gadus macrocephalus. Predictions of cod CPUE in the inner shelf (Cod North, $\mathrm{kg} \mathrm{ha}^{-1}$ ) as a function of the cod found in the full survey area (total cod, $\mathrm{kg} \mathrm{ha}^{-1}$ ) and the Pacific Decadal Oscillation index (PDO). Predictions were derived from a Generalized Additive Model (GAM) fitted to the available time series of cod

term). Thus, the inner and middle portion of the shelf may be an overflow region, occupied when thermal conditions are favorable (i.e. wide gateway) and when stock abundance is high. Indeed, this hypothesis is supported by the significant interaction between PDO and cod CPUE of the GAM analysis. A wider dispersion at higher population size has also been found in several flatfish stocks of the Bering Sea (McConnaughey 1995), as well as for Atlantic cod (Swain \& Wade 1993).

There are some aspects of the historical interaction of cod and capelin in the eastern Bering Sea that are less clear. In the early 1970s, water temperatures were on average colder over the Bering Sea shelf, and capelin were more abundant in the southern part of the shelf, all the way to the Pribilof Islands. Naumenko (1996) speculated that a southern aggregation of capelin may have been a distinct stock from the one distributed farther to the northwest, as indicated by unique values of size- and maturity-at-age of the Pribilof aggregation. During the 1970s, feeding incidences of cod on capelin were also located further to the south and capelin were found in the diet of cod below $57^{\circ}$ latitude (Fig. 6) and in the diet of black-legged kittiwakes near the Pribilof Islands (Hunt et al. 1996). In the late 1970s, the increase of water temperature, concomitant with an increase of recruitment and biomass of many groundfish predators (e.g. cod and pollock), coincided with a sharp decline of the southern capelin stock. As a consequence, capelin were no longer found in the diet of seabirds from around the Pribilof Islands (Hunt et al. 1996), and the incidence of cod feeding on capelin decreased and shifted further to northern waters (Fig. 6). The sharp decline of capelin from the outer shelf of the Bering Sea could have been the result of increased predation and competition pressure from the rising abundances of adult and juveniles gadids, respectively.

In other sub-arctic systems, where cod-capelin trophic interactions are much higher than in the Bering Sea, their overlap is not severely constrained by landscape features. In the Barents Sea, for example, ice forms along the eastern coastal margin and to the north of Spitzbergen, but not over the southern shelf, which is bathed by the warm North Cape Current, a branch of the Norwegian Atlantic Current (Wadhams 1986). Temperatures over the shelf region of the Barents Sea only reach 3 to $5^{\circ} \mathrm{C}$ in winter and 5 to $10^{\circ} \mathrm{C}$ in summer (Johannessen 1986). Cod feed on capelin all year round, but most heavily in the winter (Dolgov 2002), when capelin migrate through the main cod distribution to spawn in the northern shores of Norway and Russia. Thus, there are 2 critical landscape differences between the Bering and the Barents Sea that influence the extent of the cod-capelin linkage. First, the lack of thermal barrier in the Barents Sea places cod and capelin in greater proximity. Second, the migratory movements that have developed in response to the location of suitable spawning grounds and feeding habitats, force capelin in the Barents Sea to migrate through the center of immature cod habitat during winter.

The overlap metric calculated in this study (Eqs. 3, 4 $\& 5)$ bears resemblance to the 'potential contact' statistics developed by O'Driscoll et al. (2000) to measure the scale-dependent contact between cod and capelin in the Newfoundland waters (e.g. Rose \& O'Driscoll 2002). However, our metric is spatially-explicit and not scale-dependent. In other words, we choose to fix the scale of comparative distance $\left(d_{\max }\right)$, while changing the locations over which such distance is applied. Our metric is, therefore, suitable for analyses where the location of the overlap between 2 species is desirable, besides the overlap quantity. This is an important objective of our study; however, our metric is not suited to study variation of overlap over different scales of contact.

Some discussion on data limitations is appropriate. Bottom temperatures in the Bering Sea may change considerably within a short period of time (Stabeno et al. 1999), and thus the inferred width of the thermal gateway, although obtained at the same time as the biological measurements of distribution, may not be 
representative of the history of thermal conditions throughout the summer. Furthermore, the sampling grid of the AFSC bottom trawl survey was standardized after 1979. The interannual variability that we reported in term of species distribution and overlap patterns may, therefore, reflect a difference in the distribution of sampling effort. However, our conclusions with regard to pre-1979 cod-capelin interactions should be robust to the changes in sampling grid. From the results of our analysis, we report that in those early years, the overlap between cod and capelin was located further to the south and that it was overall lower compared to later years. It is worth noting that the southern portion of the Bering Sea shelf was consistently sampled, even during the early years of the survey program. There may have been more capelin further north, but the important point is that there were no cod there, as shown by the catch records of the AFSC surveys that did extend into the inner shelf in the 1970s (i.e. 1975 and 1976) and by other authors as well (e.g. Bakkala 1984).

The results presented in our study were derived from summer surveys. However, summer should be the time of the year when cod and capelin in the Bering Sea are most likely to overlap in distribution. Although little is known about capelin seasonal movements, it appears that after spawning in summer, a part of the capelin population may migrate northwards towards feeding grounds in the northern Bering Sea. The distribution of cod, in both winter and summer, is consistently located further south than that of capelin. In fact, tagging results from the eastern Bering Sea indicate the possibility of 2 major cod over-wintering and spawning areas: one just west of the Pribilof Islands and the other to the northeast of Unimak Pass (Shimada \& Kimura 1994). The former seems to be populated by fish that feed in summer on the northern shelf/slope and the latter by fish that feed in waters over the middle and inner shelves.

In marine pelagic systems, spatial considerations, linked with climate forcing, are seldom accounted for in population dynamics models, even though the mechanisms that promote overlap variability can indirectly have profound effects on population demographic rates. In this regard, we believe that our study, focusing on the landscape dynamics, enables a better understanding of the mechanisms of marine population variability in the presence of climate forcing.

Acknowledgements. We are grateful to G. Walters and G. Lang for the use of bottom-trawl survey and cod diet data, respectively. Valuable comments from J. Duffy-Anderson, J. Durant, G. Ottersen, J. Napp, T. Schweder and 2 anonymous reviewers improved our manuscript. This research is contribution FOCI-0540 to NOAA's Fisheries-Oceanography Coordinated Investigations.

\section{LITERATURE CITED}

Bakkala RG (1984) Pacific cod of the eastern Bering Sea. Int North Pac Fish Comm Bull 42:157-179

Bartlett D, Carter RWG (1991) Seascape ecology: the landscape of the coastal zone. Ekologia (CSFR)/Ecology(CSFR) 10:43-53

Benson AJ, Trites AW (2002) Ecological effects of regime shifts in the Bering Sea and eastern North Pacific Ocean. Fish Fish 3:95-113

Bond NA, Overland JE, Spillane M, Stabeno P (2003) Recent shifts in the state of the North Pacific. Geophys Res Lett 30(23):1-4

Brodeur RD, Wilson MT, Walters GE (1999) Forage fishes in the Bering Sea: distribution, species associations, and biomass trends. In: Loughlin TR, Ohtani K (eds) Dynamics of the Bering Sea. University of Alaska Sea Grant Program Rept. No. 99-03, Fairbanks, AK, p 509-536

Carscadden JE, Frank KT, Leggett WC (2001) Ecosystem changes and the effects on capelin (Mallotus villosus), a major forage species. Can J Fish Aquat Sci 58:73-85

Ciannelli L, Chan KS, Bailey KM, Stenseth NC (2004) Nonadditive effects of environmental variables on the densitydependent survival of a large marine fish population. Ecology 85(12):3418-3427

Cooney RT (1981) Bering sea zooplankton and micronekton communities with emphasis on annual production. In: Hood DW, Calder JA (eds) The eastern Bering Sea shelf: oceanography and resources, Vol 2. US Government Printing Office, Washington DC, distributed by the University of Washington Press, Seattle, WA, p 947-974

Cooney RT, Coyle KO (1982) Trophic implications of crossshelf copepod distributions in the southeastern Bering Sea. Mar Biol 70:187-196

Dolgov AV (2002) The role of capelin (Mallotus villosus) in the foodweb of the Barents Sea. ICES J Mar Sci 59:1034-1045

Frost KJ, Lowry LF (1981) Food and trophic relationships of cetaceans in the Bering Sea. In: Hood DW, Calder JA (eds) The eastern Bering Sea shelf: oceanography and resources, Vol 2. US Government Printing Office, Washington DC, distributed by the University of Washington Press, Seattle, WA, p 827-836

Hastie TJ, Tibshirani RJ (1990) Generalized additive models. Chapman \& Hall, London

Hunt GL Jr, Decker MB, Kitaysky AS (1996) Fluctuations in the Bering Sea ecosystem as reflected in the reproductive ecology and diets of kittiwakes on the Pribilof Islands, 1975 to 1990. In: Greenstreet S, Tasker M (eds) Aquatic predators and their prey. Blackwell, London, p 142-153

Johannessen OM (1986) Brief overview of the physical oceanography. In: Hurdle BG (ed) The nordic seas. Springer, Berlin, p 103-124

Laevastu T, Larkins HA (1981) Marine fisheries ecosystem: its quantitative evaluation and management. Fishing News Books, Surrey

Lilly GR (1991) Interannual variability in predation by cod (Gadus morhua) on capelin (Mallotus villosus) and other prey off southern Labrador and northeastern Newfoundland. ICES Mar Sci Symp 193:133-146

Lilly GR (1994) Predation by Atlantic cod on capelin on the southern Labrador and Northeast Newfoundland shelves during a period of changing spatial distribution. ICES Mar Sci Symp 198:600-611

Livingston PA (1991) Groundfish food habits and predation on commercially important prey species in the eastern Bering Sea from 1984-86. NOAA Tech Memo NMFS F/NWC207:31-88 
Livingston PA, deReynier Y (1996) Groundfish food habits and predation on commercially important prey species in the eastern Bering Sea from 1990 to 1992. NOAA AFSC Processed Report 96-04

Loughlin TR, Sukhanova IN, Sinclair EH, Ferraro RC (1999) Summary of biology and ecosystem dynamics in the Bering Sea. In: Loughlin TR, Ohtani K (eds). Dynamics of the Bering Sea. University of Alaska Sea Grant Program Report No. 99-03, Fairbanks, AK, p 387-407

Lowry LF, Frost KJ (1981) Feeding and trophic relationships of Phocid seals and walruses in the eastern Bering Sea. In: Hood DW, Calder JA (eds) The eastern Bering Sea shelf: oceanography and resources, Vol 2. US Government Printing Office, Washington DC, distributed by the University of Washington Press, Seattle, WA, p 813-824

Mantua NJ, Hare SR (2002) The Pacific decadal oscillation. J Oceanogr 58:35-44

McConnaughey RA (1995 Changes in geographic dispersion of eastern Bering Sea flatfish associated with changes in population size. In: Proc Int Symp on North Pacific Flatfish. Alaska Sea Grant College Program, p 384-405

Mito K (1974) Food relationships among benthic fish populations in the Bering Sea-on the Theragra chalcogramma fishing grounds in October and November of 1972. Masters thesis, Hokkaido University Graduate School, Hakodate (in Japanese)

Mito K (1979) Food relationships among benthic fish populations in the Bering Sea. PhD thesis, Hokkaido University Graduate School, Hakodate (in Japanese)

Nakken O (1994) Causes of trends and fluctuations in the ArctoNorwegian cod stock. ICES Mar Sci Symp 198:212-228

Naumenko EA (1996) Distribution, biological condition, and abundance of capelin (Mallotus villosus) in the Bering Sea. In: Mathisen OA, Coyle KO (eds) Ecology of the Bering Sea. University of Alaska Sea Grant College Program Report No 96-01, Fairbanks, AK, p 237-256

Nebenzahl D (2001) 2001 bottom trawl survey of the eastern Bering Sea continental shelf. NOAA, AFSC Processed Report 2001-08, Alaska Fisheries Science Center, National Marine Fisheries Service, National Oceanographic and Atmospheric Administration, Seattle, WA, p 164

O'Driscoll RL, Schneider DC, Rose AG, Lilly GR (2000) Potential contact statistics for measuring scale-dependent spatial patterns and associations: an example of northern cod (Gadus morhua) and capelin (Mallotus villosus). Can J Fish Aquat Sci 57:1355-1368

Palsson OK (1997) Predator-prey interactions of demersal fish species and capelin (Mallotus villosus) in Icelandic waters. In: Forage Fishes in Marine Ecosystems. Proceedings of

Editorial responsibility: Otto Kinne (Editor-in-Chief), Oldendorf/Luhe, Germany the International Symposium on the role of forage fishes in marine ecosystems, Anchorage, AK, November 13-16 1996. University of Alaska Sea Grant College Program Report No 97-01, Fairbanks, AK, p 105-126

Perry RI, Stocker M, Fargo J (1994) Environmental effects on the distributions of groundfish in Hecate Strait, British Columbia. Can J Fish Aquat Sci 51:1401-1409

Rose GA, Leggett WC (1990) The importance of scale to predator-prey spatial correlations: an example of Atlantic fishes. Ecology 71:33-43

Rose GA, O'Driscoll RL (2002) Capelin are good for cod: Can the northern stock rebuild without them? ICES J Mar Sci 59:1018-1026

Shimada AM, Kimura DK (1994) Seasonal movements of Pacific cod, Gadus macrocephalus, in the eastern Bering Sea and adjacent waters based on tag-recapture data. Fish Bull 92:800-816

Sinclair E, Loughlin TR, Pearcy W (1994) Prey selection by northern fur seals (Callorhinus ursinus) in the eastern Bering Sea. Fish Bull 92:144-156

Springer AM, Murphy EC, Roseneau DG, McRoy CP, Cooper BA (1987) The paradox of pelagic food webs in the northern Bering Sea-I. Seabird food habits. Cont Shelf Res 7: 895-911

Stabeno PJ, Schumacher JD, Ohtani K (1999) The physical oceanography of the Bering Sea. In: Loughlin TR, Othani $\mathrm{K}$ (eds) Dynamics of the Bering Sea. Alaska Sea Grant Publication AK-SG-99-03, Fairbanks, AK, p 1-28

Swain DP, Wade EJ (1993) Density-dependent geographic distribution of Atlantic cod (Gadus morhua) in the southern Gulf of St. Lawrence. Can J Fish Aquat Sci 50:725-733

Taylor WW, Hayes DB, Ferreri CP, Lynch KD, Newman KR, Roseman EF (2002) Integrating landscape ecology into fisheries management: a rationale and practical considerations. In: Liu J, Taylor WW (eds) Integrating landscape ecology into natural resource management. Cambridge University Press, Cambridge, p 366-389

Thompson GG, Dorn MW (2003) Assessment of the Pacific cod stock in the eastern Bering Sea and Aleutian Islands area. In: Stock assessment and fishery evaluation report for the groundfish resources of the Bering Sea/Aleutian Islands regions. North Pacific Fishery Management Council, Anchorage, AK

Turner MG (1989) Landscape ecology: the effect of pattern on process. Annu Rev Ecol Syst 20:171-197

Wadhams P (1986) The ice cover. In: Hurdle BG (ed) The Nordic seas. Springer, Berlin, p 21-87

Wood SJR (2000) Modelling and smoothing parameter estimation with multiple quadratic penalties. J R Stat Soc B 62(2):413-428

Submitted: September 20, 2004; Accepted: December 23, 2004 Proofs received from author(s): April 6, 2005 